\title{
The microsomal calcium-ATPase inhibitor thapsigargin is a neurotoxin in perinatal rodent brain
}

\author{
Faye S. Silverstein and Carrie Nelson \\ Departments of Pediatrics and Neurology, Lniversity of Michigan, Ann Arbor, MI 48109 (USA)
}

(Received 12 May 1992; Revised version received 8 July 1992; Accepted 8 July 1992)

Key words: Calcium; Neurotoxicity; Thapsigargin; Calcium ATPase; Perinatal; Rodent

\begin{abstract}
Thapsigargin is a potent inhibitor of the microsomal calcium-ATPase. We hypothesized that thapsigargin-induced liberation of calcium from sequestered intracellular sites could result in irreversible brain injury. To assess neurotoxicity, intracerebral injections of $0.1-100 \mathrm{nmol}$ thapsigargin were performed in 7-day-old rats, and the severity of injury was assessed 5 days later by microscopy and measurements of lesioned areas. We found that thapsigargin elicited dose-dependent tissue injury in perinatal rodent brain.
\end{abstract}

Thapsigargin, an inhibitor of the microsomal calciumATPase, has proven to be a valuable agent for study of the regulation of calcium homeostasis in vitro $[7,8,11$, 14-16]. It is a plant-derived sesquiterpene lactone, and a (non-phorboid) tumor promoter that releases intracellular calcium stores in many cell types. Thapsigargin stimulates release of intracellular calcium both from microsomal pools sensitive to inositol 1,4,5-trisphosphate $\left(\mathrm{IP}_{3}\right)$, and also from stores that are unaffected by $\mathrm{IP}_{3}[1]$. In rat brain-derived microsomes, $10 \mathrm{nM}$ thapsigargin maximally inhibited ATP-dependent calcium accumulation [16]. In cultured hepatocytes, exposure to $200 \mathrm{nM}$ thapsigargin elicited rapid and sustained increases in free intracellular calcium concentration $\left(\left[\mathrm{Ca}^{2+}\right]_{i}\right)[6]$. In cultured muscle cells, 30-min exposure to thapsigargin inhibited cell division and suppressed DNA and protein synthesis, but did not alter cell viability or morphology [4]. The in vivo actions of this drug have not been reported.

Since increased free $\left[\mathrm{Ca}^{2+}\right]_{i}$ may play a pivotal role in the pathogenesis of neuronal injury, we hypothesized that thapsigargin could be a useful agent for study of calcium-mediated brain injury in vivo. Since developing neurons may be particularly susceptible to calcium overload because of immaturity of intracellular buffering sys-

Correspondence: F.S. Silverstein, Room 6028, Kresge II Building, University of Michigan. Ann Arbor. MI 48109-0570, USA. Fax: (1) (313) 764-4279. tems (e.g. calcium binding proteins such as calbindin [13]), we tested the neurotoxicity of thapsigargin by injecting this compound intracerebrally in 7-day-old rats.

On post-natal day (PND) 7, rats (Sprague-Dawley, Charles River) were anesthetized with ether. Thapsigargin was injected stereotactically into right posterior striatum, using previously described methods [10]. In brief, animals were positioned in a Kopf small animal stereotaxic apparatus, a mid-line scalp incision was made, and bregma was used as a surface landmark to determine the injection site (coordinates: AP $-2 \mathrm{~mm}, \mathrm{~L}$ $2.5 \mathrm{~mm}$. D $4 \mathrm{~mm}$ ). The skull was penetrated with a $22-$ gauge needle, and thapsigargin (dissolved in $1 \mu 1 \mathrm{DMSO}$ ) was injected slowly with a Hamilton syringe (doses tested: $0.1,0.5,1,10,25,50$ and $100 \mathrm{nmol}, n=3-5 /$ group). Six control animals received injections of equal volumes of DMSO. The majority of animals that received $\geq 25$ nmol thapsigargin died acutely. Overall, 15 thapsigargininjected animals survived to PND 12; they were killed by decapitation, and brains were removed intact and rapidly frozen. The surgical protocol was approved by the University of Michigan Animal Care and Use Committee.

20- $\mu \mathrm{m}$ coronal frozen brain sections were prepared, post-fixed with paraformaldehyde and stained for Nissl substance with Cresyl violet. To quantitate the severity of tissue injury, an image analyzer (MCID. Imaging Research Inc., St. Catherines, Ont.) was used to estimate the extent of injury in each brain. Areas in which Nissl-staining was disrupted were identified, outlined with a cursor, 

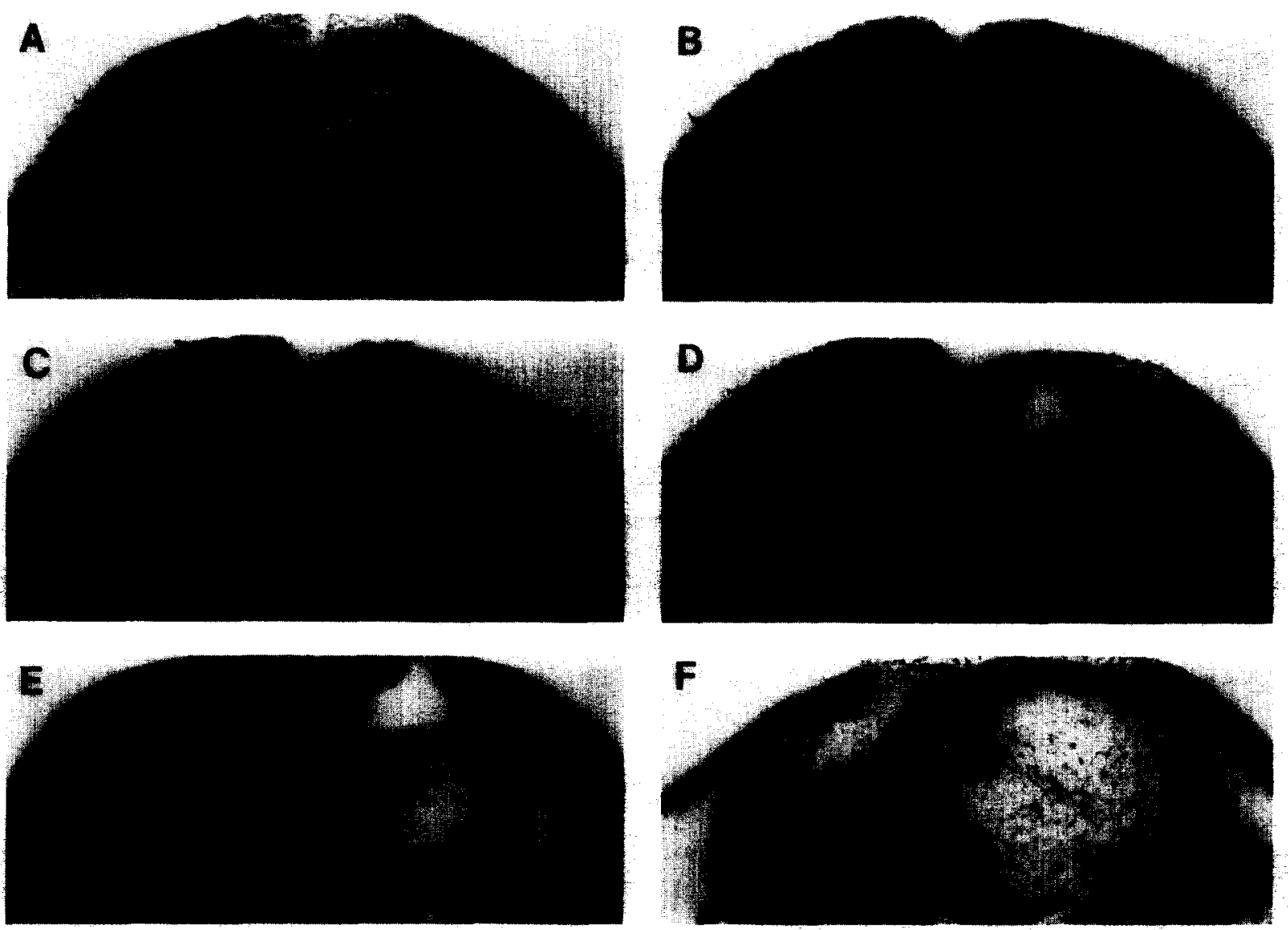

Fig. 1. Photographs of Nissl-stained coronal brain sections, prepared from PND 12 animals that had received intracerebral injections of DMSO (A) or thapsigargin $(0.1$ (B), 0.5 (C), 1 (D), 10 (E) or 25 (F) nmol) on PND 7 (see text for Methods). These photographs demonstrate the histopathologic features of thapsigargin-induced lesions. In the DMSO-injected animal (A), there are subtle lesions in the pyramidal cell layer along the injection track (arrowheads). In the brains from animals that received thapsigargin, lesions of increasing severity are apparent. The lowest dose tested (B) elicited subtle lesions in the pyramidal cell layer. similar to those elicited by DMSO; administration of 0.5 nmol (C) elicited more extensive injury, with prominent loss of dentate gyrus and CA4 neurons in the example shown (arrowheads). With higher doses, injury also extonded into the overlying corpus callosum (D,E). In a single animal that survived for 5 days after receiving 25 nmol thapsigargin ( $F$ ), there was widespread tissue injury, with obliteration of major anatomic landmarks.

and measured $(\geq 10$ sections/brain, close to the region of maximum injury) and group means were calculated.

With our injection methods, if saline is administered, the needle track can sometimes be identified (distortion or disruption of cellular integrity along the injection track, most evident in the hippocampal pyramidal cell layer). In 4/6 DMSO-injected animals, focal cell loss adjacent to the injection track was detected (as in Fig. 1A) and in $2 / 6$ injury extended up to $2 \mathrm{~mm}$ from the track. In all surviving thapsigargin-lesioned animals, there was evidence of brain injury, extending to a variable degree from the injection site (Fig. 1B-F). In the 3 animals that received the lowest dose of thapsigargin $(0.1 \mathrm{nmol})$, there was discrete cell loss in the pyramidal cell layer adjacent to the injection site (Fig. 1B); in 1/3, the hippocampus was distorted and there was enlargement of the adjacent lateral ventricle (area of injury measurements could not be reliably obtained from this brain). In all animals that received doses of thapsigargin $\geq 0.5 \mathrm{nmol}$ there was more widespread tissue injury extending from the injection site. At higher doses, in addition to prominent neuronal loss, there was cystic necrosis of overlying corpus callosum (as in Fig. 1D,E). At the highest dose tested compatible with survival ( $25 \mathrm{nmol}$ ), there was massive necrosis and complete disruption of tissue integrity (Fig. 1F). Fig. 2 compares the areas of the lesions in animals that received $0.1-25 \mathrm{nmol}$ thapsigargin; the extent of injury increased with higher doses $\left(r^{2}=0.81, P=0.0001\right.$, regression analysis).

Variations in the sites of maximal injury were readily attributable to slight differences in the accuracy of needle placement. In instances where the injection site was, inadvertently, displaced either medially or laterally, the histologic features and size of the resulting lesions were similar. There was no apparent regional or cellular selectivity in the distribution of injury. In the hippocampus. for example, CA 1 and CA 3 pyramidal cells and dentate gyrus neurons appeared equally susceptible to injury. 


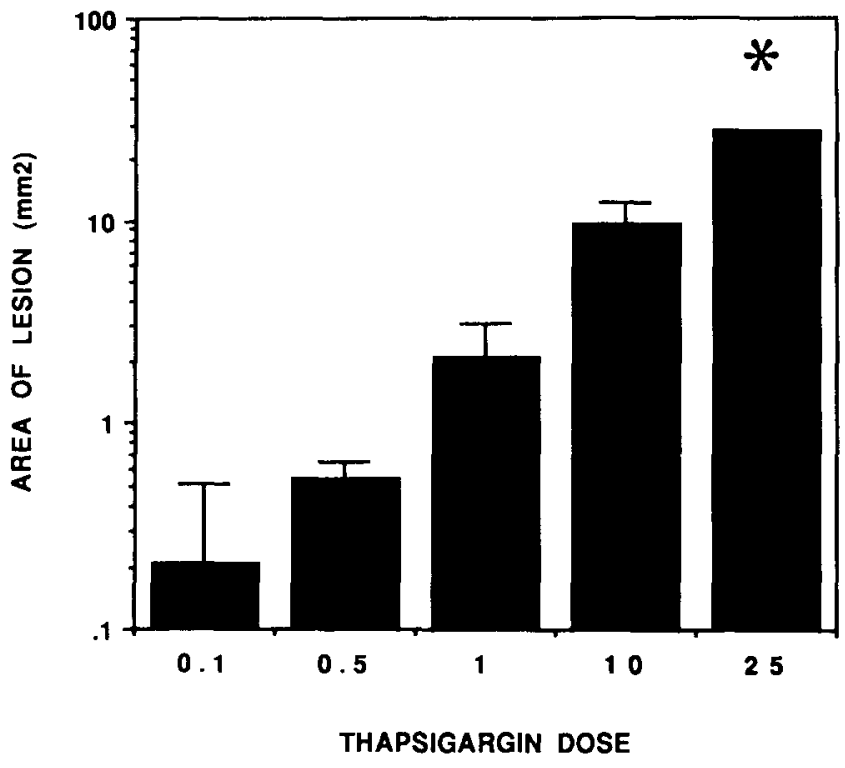

Fig. 2. This graph compares the extent of brain injury that resulted after intracerebral injections of $0.1,0.5,1,10$ or $25 \mathrm{nmol}$ thapsigargin (see text for Methods). Animals were lesioned on PND 7, and histopathology was assessed on PND 12 ( $n=2$ 5/group, except for 25 nmol. $n=1$ ). Coronal brain sections were prepared and Nissl-stained. The site of maximal injury was identified, and the area of injury was outlined and measured in at least 10 sections/brain, close to this site, using a computerized image analysis system (MCID. Imaging Resources, St. Catherines, Ont.). Values are expressed as mean \pm S.E.M. (except for $25 \mathrm{nmol}$. $n=1$ ); note that $y$-axis is logarithmic. * indicates $r^{2}=0.81, P=0.0001$. regression analysis, comparing doses of thapsigargin administered and areas of injury.

Similarly, there was no apparent sparing of white matter tracts, and more severe lesions encompassed corpus callosum. At higher doses, the lesions extended into posterior striatum and thalamus.

Our results indicate that thapsigargin is a potent neurotoxin in perinatal rodent brain. In vitro thapsigargin effectively inhibits Ca-ATPase at sub-nanomolar concentrations [11]. Although the thapsigargin concentration attained in brain tissue is difficult to estimate accurately, the in vivo toxic effects were observed in a similar range. There are no data about the pharmacokinetics of thapsigargin and it is impossible to predict the likely duration of exposure to the compound after intracerebral injection. If thapsigargin blocked microsomal $\mathrm{Ca}^{2+}$ uptake and intracellular calcium buffering and sequestration mechanisms were inadequate to compensate, sustained elevations in free $\left[\mathrm{Ca}^{2+}\right]_{\mathrm{i}}$ could result. In addition. there is evidence of functional coupling between intracellular $\mathrm{Ca}^{2+}$ pools and the permeability of the plasma membrane to $\mathrm{Ca}^{2+}$ in neuronal cells; depletion of intracellular pools could increase plasma membrane $\mathrm{Ca}^{2+}$ permeability, and thereby lead to further increases in free $\left[\mathrm{Ca}^{2+}\right]_{\mathrm{i}}[8,14] .\left[\mathrm{Ca}^{2+}\right]_{i}$ was not measured in lesioned tissue. and the possibility that an unrecognized mechanism of action, rather than $\mathrm{Ca}^{2+}$ mobilization, was responsible for thapsigargin's toxicity cannot be excluded. Yet, it is readily conceivable that brain injury did result from the deleterious effects of elevated free $\left[\mathrm{Ca}^{2+}\right]_{i}$.

Considerable data indicate that increased free $\left[\mathrm{Ca}^{2+}\right]_{i}$ is an important mediator of ischemic and excitotoxic brain injury $[2,3,5,9,12]$. The pathophysiologic factors that contribute to the rise in free $\left[\mathrm{Ca}^{2+}\right]_{i}$ with these types of injury include increased influx (through both voltageand neurotransmitter-gated channels), release from metabolically compromised mitochondria, and in some cell types suppression of the sodium-dependent calcium exchanger. Whether pathologic increases in the amount of $\mathrm{Ca}^{2+}$ released from microsomal stores occur in these settings is unknown. Potential deleterious effects of elevated free $\left[\mathrm{Ca}^{2+}\right]_{i}$ include activation of multiple degradative enzymes. uncoupling of oxidative phosphorylation and energy depletion: at what point these events induce irreversible neuronal injury and the factors that determine cellular differences in susceptibility remain unknown.

One of the most surprising features of the histopathologic distribution of injury was its uniformity. The neuronal populations examined (in hippocampal pyramidal cell layer and dentate gyrus, striatum, cortex and thalamus) and white matter tracts. all appeared equally susceptible to injury. Some degree of cellular or regional selectivity might be detectable if doses close to the toxicity threshold or different intracerebral injection sites were tested. In vitro, the majority of studies of thapsigargin have used microsomes or permeabilized cells in which toxicity would be difficult to discern. Only one study [4] has examined the effects of thapsigargin on cellular functioning. In cultured smooth muscle cells exposure to thapsigargin depleted the $I P_{3}$-sensitive calcium pool but caused no morphologic changes or mitochondrial dystunction; however. cell division was completely blocked and DNA and protein synthesis were markedly suppressed. Factors accounting for the relative resistance of these cells to calcium-induced injury are uncertain: it is possible that adaptive mechanisms prevented sustained elevations in free $\left[\mathrm{Ca}^{2+}\right]_{i}$ in these cells. It is also conceivable that the perinatal brain is particularly susceptible to thapsigargin because of immaturity of calcium-buffering systems e.g. calbindin [17]. It will be interesting to determine if there are age-related differences in susceptibility to thapsigargin neurotoxicity, and if they can be attributed to differences in the magnitude and duration of increased free $\left[\mathrm{Ca}^{2}\right]_{i}$ attained. Measurements of changes in $\left[\mathrm{Ca}^{2+}\right]_{i}$ in thapsigargin-lesioned animals will be essential to elucidate its mechanism of neurotoxicity in vivo.

In summary, these results indicate that thapsigargin, a 
potent inhibitor of the microsomal $\mathrm{Ca}^{2+}$-ATPase, is neurotoxic in vivo in perinatal rodent brain. This drug may represent an important experimental tool for studying calcium-mediated injury in vivo, for understanding regional and developmental differences in susceptibility to certain forms of brain injury, and, in particular, for pharmacologic dissection of the potential contribution of the microsomal $\mathrm{Ca}^{2+}$ pool to the evolution of neuronal injury.

This work was supported by USPHS Grant 26142 and a Grant-in-Aid from the American Heart Association of Michigan.

1 Bian, J., Ghosh, T.K., Wang, J.C. and Gill, D.L., Identification of intracellular calcium pools, J. Biol. Chem., 266 (1991) 8801-8806.

2 Choi, D.W., Ionic dependence of glutamate neurotoxicity, J. Neurosci., 7 (1987) 369-379.

3 Choi, D.W. and Rothman, S.M., The role of glutamate neurotoxicity in hypoxic-ischemic neuronal death, Annu. Rev. Neurosci., 13 (1990) 171-182.

4 Ghosh, T.K., Bian, J.H., Short, A.D., Rybak, S.L. and Gill, D.L., Persistent intracellular calcium pool depletion by thapsigargin and its influence on cell growth, J. Biol. Chem., 266 (1991) $24690-7$.

5 Greenberg, J.H., Uematsu, D., Araki, N., Hickey, W.F. and Reivich, M., Cytosolic free calcium during focal cerebral ischemia and the effects of nimodipine on calcium and histologic damage, Stroke, 21, Suppl. IV (1990) IV72-IV77.

6 Llopis, J., Cow, S.B., Kass, G.E., Gahm, A. and Orrenius, S., Comparison between the effects of the microsomal $\mathrm{Ca}^{2+}$-translocase inhibitors thapsigargin and 2,5-di-(t-butyl)-1,4-benzohydroquinone on cellular calcium fluxes, Biochem. J., 277 (1991) 553-556.

7 Lytton, J., Westlin, M. and Hanley, M.R., Thapsigargin inhibits the sarcoplasmic or endoplasmic reticulum Ca-ATPase family of calcium pumps, J. Biol. Chem., 266 (1991) 17067-17071.

8 Mason, M.J., Garcai-Rodroguez, C. and Grinsetine, S., Coupling between intracellular calcium stores and the calcium permeability o: the plasma membrane - comparison of the effects of thapsigargin. 2,5-di-(tert-butyl)-1,4-hydroquinone, and eyclopiazonic acid in rat thymic lymphocytes, J. Biol. Chem., 266 (1991) 2085620862.

9 Mattson, M.P., Guthrie, P.B. and Kater, S.B.. A role for Na -dependent $\mathrm{Ca}^{2+}$ extrusion in protection against neuronal excitotoxicity, FASEB J., 3 (1989) 25192526.

10 McDonald, J.W., Roeser, N.F., Silverstein. F.S. and Johnston, M.V., Quantitative assessment of neuroprotection against NMDAinduced brain injury, Exp. Neurol., 106 (1989) $289 \cdots 296$.

11 Sagara, Y. and Inesi, G., Inhibition of the sarcoplasmic reticulum Ca transport ATPase by thapsigargin at subnanomolar concentrations, J. Biol. Chem., 266 (1991) 13503-13506.

12 Siesjo, B.K. and Bengtsson, F, Calcium fluxes, calcium antagonists, and calcium-related pathology in brain ischemia, hypoglycemia, and spreading depression: a unifying hypothesis, J. Cereb. Blood Flow Metab., 9 (1989) 127 140.

13 Sloviter, R.S., Calcium binding protein (Calbindin-D 28k) and parvalbumin immunocytochemistry: localization in the rat hippocampus with specific reference to the selective vulnerability of hippocampal neurons to seizure activity, J. Comp. Neurol., 280 (1989) 183196

14 Takemura, H., Ohshika, H., Yokosawa, N., Oguma, K. and Thastrup $O$., The thapsigargin-sensitive intracellular calcium pool is more important in plasma membrane calcium entry than the IP3 sensitive intracellular calcium poot in neuronal cell lines, Biochem. Biophys. Res. Commun., 180 (1991) 1518-1526.

15 Thastrup, O., Cullen, P.H.J.. Drobak, B.K., Hanley, M.R. and Dawson, A.P., Thapsigargin, a tumor promoter, discharges intracellular calcium stores by specific inhibition of the endoplasmic reticulum calcium-ATPase, Proc. Natl. Acad. Sci. USA, 87 (1990) 24662470 .

16 Verma, A.. Hirsch, D.J., Hanley, M.R. et al., Inositol trisphosphate and thapsigargin discriminate endoplasmic reticulum stores of calcium in rat brain, Biochem. Biophys. Res. Commun.. 172 (1990) 811-816.

17 Wasterlain, C.G. et al. In C.G. Wasterlain and P. Vert (Eds.), Neonatal Seizures, Raven, New York, 1990, pp. 69-81. 